\title{
A escrita académica: um jogo de forças entre a geração de ideias e a sua concretização
}

\author{
Academic writing: a power game between the generation and accomplishment of ideas
}

\section{Maria da Graça Lisboa Castro Pinto}

Faculdade de Letras da Universidade do Porto - UP - Porto - Portugal

\begin{abstract}
Resumo: Pretende-se, neste texto, olhar para o autor de um trabalho académico como um tecelão que, no seu labor de reescrita assente em escrita, combina informação de várias proveniências com vista a conferir à sua produção textual a originalidade esperada em resultado da pesquisa efetuada. Referem-se diferentes conceitos associados à originalidade (autoria, identidade, voz, posição, atribuição, citação, paráfrase, intertextualidade transgressiva, plágio e "patchwriting") e apela-se à importância de saber usar as fontes devidamente, após uma leitura cuidada, profunda e crítica das mesmas, a fim de que a interpretação se sobreponha à reprodução, a intertextualidade não seja transgressiva e subsequentemente o "patchwriting" ou mesmo o plágio só possam ser tolerados como medida pedagógica numa fase inicial da composição. Ademais, lançam-se pistas de intervenção para ajudar os estudantes a encontrarem a sua voz de autores e sublinha-se que a escrita deve ser entendida como um hábito, como uma disciplina, como uma luta e como um ofício que espera muito rigor e empenhamento por parte de quem a pratica.
\end{abstract}

Palavras-chave: Escrita académica. Geração de ideias. Fontes. Originalidade.

\begin{abstract}
This text aims at viewing the author of academic writing as a weaver who combines information from different research sources into his/her production in order to achieve the degree of originality expected at this level. This implies dealing with different concepts associated with originality, such as authorship, identity, voice, position, attribution, citation, paraphrase, transgressive intertextuality, plagiarism and patchwriting. Furthermore attention is drawn to the proper use of sources after careful critical reading so that interpretation will replace reproduction and intertextuality will not be transgressive, bearing in mind that patchwriting or even plagiarism may only be tolerated in an early stage of written production. Moreover, students are given intervention cues so as to help them find their own voices as authors, and writing is highlighted as a habit that requires discipline and struggling as well as a craft that implies rigour and commitment.
\end{abstract}

Keywords: Academic writing. Generating ideas. Sources. Originality. 


\section{Nota de abertura}

Um título deve dizer muito do texto que designa, espelhar com clareza as intenções do seu autor e manifestar uma deferência particular para com o leitor. Em suma: um título merece ser objeto de uma boa escolha sob pena de poder frustrar expectativas, quando anuncia mais do que o que oferece, ou de afastar o público, quando não se compagina com a qualidade do conteúdo da produção textual que rotula.

Discorrer, embora brevemente, sobre um título como acaba de ser feito só pode justificar-se na medida em que a problematização em torno de um trabalho académico pode principiar exatamente por essa componente tão breve e promissora da sua estruturação (ver, por exemplo, PINTO, 2009).

Lancemos então um olhar mais crítico sobre o título escolhido para este texto, ou seja, "A escrita: um jogo de forças entre a geração de ideias e a sua concretização".

A temática em foco pode, para alguns, não ser criativa - não se revestir de originalidade usando um termo que se vai prestar a uma análise muito específica neste contexto e que pode ocorrer associado a um mito (PENNYCOOK, 1996) - porque acreditam que se situa do lado do "déjà vu" ou, formulado de uma maneira mais comum, porque acham que não traz nada de novo. Esse juízo, face ao que o título proposto invoca, pode encontrar explicação no facto de o escrevente/escritor já ter vivido situações na sua produção textual, nas quais foi especialmente sensível à existência de um confronto entre o toque de liberdade que emana da esfera das ideias, embora não totalmente impermeável aos condicionamentos imanentes dos conteúdos e dos objetivos visados, e a contenção provinda das exigências de um texto que as plasmará, acrescida da tarefa, nem sempre fácil, de recuperar lexicalmente a melhor escolha para a ideia que se pretende difundir.

Não admira portanto que essa experiência de escrita evoque episódios e mesmo envolvimentos, consignados no "jogo de forças" presente no título, que trabalhos de investigação na área procuram desvendar por meio de metodologias, do tipo de diários (CROWLEY, 1977; SOMMERS, 1978) ou de "think/talk aloud protocols" (PENROSE e GEISLER, 1994; YANG e SHI, 2003), que tendem a trazer para a ribalta os bastidores da escrita, interpretada neste enquadramento como processo compositivo (ver, por exemplo, CROWLEY, 1977; SOMMERS, 1979; FAIGLEY, 1986; MATSUDA, 2003) com raízes de natureza sociopolítica (CASANAVE, 2003) e não como simples produto acabado, como era conceituado na corrente retórica tradicional (ver MATSUDA, 2003).

Podemos por conseguinte prosseguir com a convicção de que o aludido "jogo de forças" não irrompe, em nenhuma hipótese, unicamente dos polos da dicotomia cognição-linguagem (ideiapalavra) quando está em análise a escrita académica, porquanto, enquanto género textual, conta com uma pluralidade de dinâmicas em atuação.

\section{0 termo "escrita" neste texto}

Certamente em consonância com a opinião de grande parte dos autores que elevam o termo "escrita" para os títulos dos seus artigos, dos seus livros ou de revistas da especialidade de que são fundadores, objetivando com isso divulgar o que se tem estudado e continua a estudar sobre a escrita, enquanto processo verbal único segundo Emig (1977) - por se identificar com "originating and creating a unique verbal construct that is graphically recorded" (p. 123) distinguindo-se assim de ler, falar e ouvir -, a nossa leitura de escrita encontra-se mais próxima da preconizada pela era do pós-processo (ATKINSON, 2003a; 2003b; MATSUDA, 2003). Na verdade, não a imaginamos desintegrada do quadro situacional que também a molda. Talvez seja interessante notar que se encontram revistas que versam a escrita na língua segunda como comprova o título "Journal of Second Language Writing". À primeira vista, pode afigurar-se insólito que a escrita na língua segunda seja selecionada por estudiosos da área quando já a escrita da língua primeira impõe, com frequência, ora 
um acompanhamento próximo no caso dos principiantes nesta atividade, ora um trabalho sistemático de reformulação em fases posteriores, motivando não raramente, neste último cenário, que se operem revisões ou reescritas de acordo com as "anomalias" detetadas nas produções (HAYES e FLOWER, 1986; D. MURRAY, 2013). Não se deve contudo excluir a necessidade de recorrer à escrita em línguas segundas, nomeadamente em inglês, a língua reconhecida pela comunicação científica, quando está em causa a escrita de textos académicos que têm como alvo atingir um público mais vasto e aparecer em publicações com mais impacto. Ainda que aconteça que a escrita do texto académico se concretize na língua do seu autor, dificilmente se concebe que esse texto tenha dispensado um levantamento bibliográfico provavelmente plurilingue ou seja desprovido de citações em línguas segundas, por norma em inglês, exigindo dessa forma um domínio de línguas por parte do autor que o capacite não só para interpretar as leituras feitas mas também para integrar as citações necessárias no texto de acolhimento, a fim de que não surjam descontinuidades na articulação interlinguística que obstaculizem a intertextualidade esperada (JAKOBS, 2003; MATSUDA, 2003; PETRIĆ, 2012). Em resumo, particularmente nas citações, está em causa a operação de conexões que são basilares na escrita. Como escreve D. Murray (2013) no seu tom tão característico: "The writer is a master weaver, rewriting before writing by making connections between pieces of information, observations, ideas, theories, memories, fears, hopes that when connected create a new meaning." (p. 13). A originalidade aludida no começo deste texto será assim atingida quando um autor conseguir criar um novo significado encadeando factos, acontecimentos, situações, sentimentos, representações de vária índole que tenha vivenciado ou testemunhado.

Espera-se que ressalte com intensidade da leitura deste texto que o termo "escrita" é usado como sinónimo de produção textual (JAKOBS, 2003), de composição (escrita) (MATSUDA 2003), de prosa (LANHAM, 2006) ou, na senda de Francisco Gomes de Matos (comunicação pessoal, 2015), de redigir. Para este académico, comparativamente a escrever, redigir localiza-se mais do lado da revisão, do processo cognitivo - processo que para nós será já da ordem do sociocognitivo - e dos efeitos ligados à comunicação e à audiência, ultrapassando uma visão de escrever que se resumiria à transferência de informação, (PENROSE e GEISLER, 1994), ao "knowledge telling" (BEREITER; BURTIS E SCARDAMALIA, 1988), à escrita como mero produto (ZAMEL, 1982; MATSUDA, 2003), que não transporia em algumas situações a fase da "mecânica da escrita" (VIGOTSKI, 1996, p. 140) ou, segundo Juel; Griffith e Gough (1986), do "spelling" (p. 244), postergando a "ideation", tida pelos autores como "the generation and organization of ideas" (p. 244) (ver também JUEL, 1988).

\section{A escrita numa leitura longitudinal}

Convirá igualmente perguntar como é captada a escrita por faixas etárias diferentes. Para obter uma resposta a esta questão, interrogámos estudantes de mestrado e crianças do ensino pré-primário e do 1.ำ ciclo do ensino básico de instituições portuguesas.

Nas respostas de estudantes de mestrado a quem foi perguntado o que era para eles escrever (PINTO, 2015), destacou-se justamente a ideia de comunicação e de trabalho não somente psicocognitivo, que se encontra naturalmente associado a uma das possíveis visões de literacia (DE LEMOS, 2002). Em contrapartida, tais respostas não foram dadas pelas crianças em fase de aprendizagem da escrita, o que demonstra que os adultos com percurso académico repercutem no ato de escrever um convívio com o material escrito que Ihes inculca uma maior afinidade com esse universo (ver STARFIELD, 2002) e um nível mais elevado de literacia (ver SHI, 2004) enquanto processo sociocultural (DE LEMOS, 2002), fruto de uma maior familiarização com diversos géneros textuais escritos (MARCUSCHI, 2001) e com as mais variadas práticas de cultivar e usar a escrita (SOARES, 2001). 


\section{As facetas solitária e solidária da escrita}

A escrita como processo ou como pósprocesso, vista numa perspetiva respetivamente cognitiva e sociocognitiva (MATSUDA, 2003), suscita prontamente posições de vária ordem sem excluir, em nossa opinião, a plausível convergência das suas facetas solitária e solidária. Se a escrita é uma atividade que se executa em geral isoladamente, excluída na circunstância a colaborativa, coadunando-se com a citada faceta solitária, ela só alcançará essa etapa depois de ter completado um percurso que a transforma também numa faceta solidária. Quanto à escrita académica, como lembra Sommers (2006), esta só prospera em resultado de uma experiência continuada com as normas que a governam, de uma instrução que a sua elaboração impõe como pré-requisito e de todo um trabalho de confronto de diferentes pontos de vista que o tópico em análise possa oferecer, quer por via escrita, recorrendo à literatura, quer por via oral, discutindo com outros especialistas. Não se pense que, para operar a argumentação inerente a um trabalho académico, resta ao autor ficar a aguardar a inspiração, tão associada, erradamente ou não, ao ato criativo da escrita (ver SINGER e BARRIOS, 2009). O levantamento do estado da arte não deve ser escamoteado e ele mais não é do que uma atividade social radicada no que contribuíram com os seus estudos outros membros da comunidade científica (ROSENBERG, 2011). Não será por acaso que D. Murray (2013) aconselha que se fale, que se converse, que se partilhem ideias antes de passar à escrita numa atitude que visa essencialmente não deixar o leitor cheio de interrogações. Este estudioso reforça ainda, a preceder a concretização da escrita, o papel do seu lado não visível (D. MURRAY, 1978), que facilmente se identifica com a sua faceta solitária.

Que se passa então de relevante nessa fase invisível da escrita, que Rohman (1965) intitula préescrita, situada antes do momento em que "the "writing idea" is ready for the words and the page" ( $p$. 106), e que leva Murray (1978) a considerá-la o "essential stage in the writing process which precedes a completed first draft" (p. 375)?

O que se deseja passar a escrito pode, no começo, parecer algo de indefinido; no entanto, aos poucos e não rejeitando um certo grau de fixação, com vista a poder ser exteriorizado terá de perder essa indefinição e ganhar corpo apoiado nos mais variados meios materiais ou humanos (D. MURRAY, 1978). Para mostrar que não está em causa uma ficção de um teórico quando se releva esta etapa da escrita, que está longe de ser meramente cognitiva dado que assenta em muitos contactos e contextos, D. Murray, no seu estilo muito peculiar e estribado nos numerosos depoimentos que colecionou durante toda a sua existência acerca das vivências de diferentes escritores, exemplifica esse trabalho preliminar à escrita apoiando-se em vários testemunhos que apontam para a espera (itálico nosso) - imaginada por vezes erroneamente como uma inércia indouta - reivindicada pela escrita (D. MURRAY, 1978). Não se presuma pois que a escrita brota de modo espontâneo, automático, prescindindo do inevitável recurso a um labor que a prepare.

Andrew e Romova (2012) também nos transmitem relatos, desta feita de estudantes, que enfatizam, em matéria de habilidades de planificação e organização com o intuito de melhorar a aprendizagem da escrita académica, a pré-escrita e o traçado de esquemas. Um dos estudantes refere: "they [pre-writing and outlining] control my ideas when I write my essay - very central" (p. A-84); outro profere: "Above all, outlining is the best thing for me [...] I feel that if I prepare the outline well and in detail, then the time of writing an essay gets shorter" (p. A84); outro adianta: "The process of [...] pre-writing and outlining [...] helped me to organise ideas simply and start to write easily" (p. A-84) e outro salienta: "the process - prewriting, outlining and so on - controls my ideas when I write my essay for Academic Writing and for Education" (p. A-84). Assinalam estes testemunhos a importância da preparação da escrita e reiteram a função que D. Murray atribui a esse estádio do processo da composição para que a 
entrada na primeira versão de um trabalho tenha sucesso.

Significa tudo isto que temos de prestar muita atenção ao que se processa antes do surgimento da versão que marca o arranque de uma produção textual. Aludiremos de um modo breve, neste texto, a expressões associadas por alguns autores a esse momento que precede a escrita e que tão claramente sustentam o que nele se passa e de que modo. $\mathrm{Na}$ década de 80 do século passado, provavelmente na sequência do repto lançado por Rohman e por D. Murray, Perl (1980) usa a expressão "felt sense" para designar 0 que um tópico pode suscitar cognitivamente, Faigley e Witte (1981) avançam a forma como escritores mais proficientes se ocupam do desenvolvimento e da revisão dos seus textos no plano mental antes de os redigirem e Zamel (1982) aduz um "inner dialogue", um momento relevante da composição posicionado no plano das ideias e a preceder 0 ato de escrita, independentemente da fase de execução em que esta se encontre. Por sua vez, já neste século, Chenoweth e Hayes (2003) fazem referência à "inner voice", situada entre a intenção e o texto, que, sendo a voz de cada autor, é mais uma vez um misto de solitário e do que a motiva, que é, para nós, da ordem do solidário.

O passo da escrita que a antecede, apesar de se afigurar tão solitário, tão cognitivo e de induzir denominações que podem ir nesse sentido, não nos permite que a apartamos do social. A terminologia utilizada é indubitavelmente forte; sem embargo, ousamos afirmar que, se há estágios da escrita como processo em que o recurso à atividade cognitiva é inevitável, tornando-a mesmo um ato solitário, não é possível descartar o que a fez chegar a esse ponto, que só pode ser da ordem do social, do solidário.

\section{A escrita académica e a originalidade}

Justifica-se, por um lado, interrogarmo-nos sobre o que se entende por originalidade na escrita académica, nas publicações científicas, e, por outro lado, equacionarmos em que medida esse género textual não se encontrará refém da literatura estudada e das imposições prescritas pela comunidade académica, condicionando as vozes dos seus autores e consequentemente a sua linguagem, a sua argumentação (CURRIE, 1998) e, por fim, a esperada criatividade. Com efeito, haverá que ter em conta que estamos perante uma modalidade de uso da língua socialmente enquadrada, sujeita a convenções, obedecendo a constrangimentos e respeitando expectativas (HYLAND, 2003),

Poderá ter também cabimento questionar se a intertextualidade da escrita académica limita a capacidade de um autor ser "the sole originator of his or her words or ideas" (CURRIE, 1998, p. 1). Não acreditamos que seja o que se passa neste género textual, visto que ele tem necessariamente de assentar numa interpretação que só pode ter a sua génese no autor que Ihe dá voz, ao resultar do cruzamento das vozes que o constituem (STARFIELD, 2002), mercê de uma análise crítica seguida da necessária síntese. Entre outras condutas, a inclusão com precisão no texto a redigir, sempre que se imponham, quer de referências à literatura (“citations") (JAKOBS, 2003) corretamente atribuídas e utilizadas com contenção, quer de citações ("quotations") (JAKOBS, 2003) introduzidas, integradas e contextualizadas acertadamente (PETRIĆ, 2012), auxiliará a suster o trabalho académico e revelará como o seu autor elabora as suas ideias, consolida os seus argumentos e reforça ou revê as suas opiniões no intento de ser original (a respeito do vaivém entre a análise e a síntese neste contexto em consonância com o empenho do autor, ver CROWLEY, 1977). Com base em Jakobs (2003), podemos dizer que no trabalho académico está em causa uma produção textual "in which writers have recourse to other texts and use them for the development of their own thoughts" (p. 894). Os autores são assim confrontados com a tarefa de analisarem as ideias dos outros, de as compararem, de as associarem e de as contrastarem entre si e com as suas, provindas estas últimas de tantas outras fontes de conhecimento que, quantas vezes, passam pelas suas experiências de vida, para, por intermédio da síntese resultante desse esforço multicognitivo, 
chegarem a uma intertextualidade que desvie a possibilidade de uma apropriação dos pensamentos e das palavras de terceiros, de que derivaria a indesejada não presença de originalidade, de voz e de autoria próprias (ver, a respeito da possível distinção entre plágio de ideias e de linguagem, PENNYCOOK, 1996). Com os convenientes ajustamentos, podemos afirmar que estamos diante de um labor multicognitivo, similar ao que é aconselhado por Odisho (2003; 2007; 2014) no que concerne ao ensino da pronúncia de uma língua estrangeira, que não vive sem a exposição ao modelo que a desencadeia, ou seja, sem o social, tão reclamado pelos que veem na escrita um processo que não vai para além da esfera do cognitivo (MATSUDA, 2003). Partilhamos a posição de Casanave (2003) quando, com fundamento na literatura, admite que as produções escritas "are increasingly viewed not just as linguistic artifacts but as socially produced and politically situated" (p. 87). $\mathrm{Na}$ realidade, um escrito académico não pode subsistir desagregado do que a sociedade/comunidade científica espera dele e do seu autor e do que outros possam ter contribuído, por via de escritos ou de dados fornecidos, para the conferir a sustentabilidade esperada. Não estamos por consequência face a textos, no caso de existirem, que não ultrapassem patamares primários da modalidade de uso da língua (MARCUSCHI, 2001) usada para os concretizar.

A escrita académica atinge com mais facilidade - aguardado pelos pares, pelos que têm afinal a última palavra em termos da qualidade da produção final, principalmente no caso da escrita destinada a ser publicada (CASANAVE, 2003), quando quem a pratica se encontra familiarizado com o discurso académico praticado pela comunidade respetiva (PENROSE e GEISLER, 1994), que se consubstancia num ato por natureza social (ver, acerca das comunidades discursivas, ANDREW e ROMOVA, 2012). Além disso, espera-se que o autor execute uma prática bem treinada de leitura das fontes, também no plano formal, para que quem o leia sinta que, por detrás da tecedura do texto, se encontram latentes combinações de perspetivas das quais, graças à síntese obrigatória, emana a originalidade esperada. Deve sentir-se que quem escreve não se refugia demasiado, premeditadamente ou por desconhecimento das normas que regem a escrita académica, em empréstimos sucessivos das ideias e das palavras de outras autorias, que, em última instância, o podem fazer correr o risco de cometer o malvisto plágio (HOWARD, 1995; CURRIE, 1998; SHI, 2008). Uma leitura cuidadosa e crítica das fontes é tanto mais proveitosa quanto alerta o leitor, mais tarde no papel de escritor, para a linguagem que está ao serviço do desenvolvimento de um texto que respeita a audiência impondo credibilidade, ou seja, para o metadiscurso específico deste género textual (HYLAND, 2004; 2008). Não se deve ignorar que o domínio desse metadiscurso radica numa literacia académica que só mesmo um contacto continuado com a escrita requerida pela academia pode ir consolidando. A leitura e a escrita devem assim encontrar-se numa relação que alargue o enfoque de cada um destes processos verbais e que concorra para ver neles uma complementaridade conducente a um mútuo enriquecimento (BUNN, 2011).

\section{Conceitos relacionados com a originalidade na escrita académica}

O exposto até ao momento em redor do termo "originalidade", pode atrair, por associação firmada na temática em discussão, toda uma gama de conceitos que é justo chamar a intervir quando a escrita é também, neste enquadramento, palavra-chave.

Entre outros termos/conceitos que podem vir agregados à originalidade devem enumerar-se: 1) a autoria (PENROSE e GEISLER, 1994; HOWARD, 1995; STARFIELD, 2002); 2) a identidade (HIRVELA e BELCHER, 2001; IVANIČ e CAMPS, 2001; CASANAVE, 2003; ABASI; AKBARI e GRAVES, 2006; STARFIELD, 2002); 3) a voz (ATKINSON, 2001; HIRVELA e BELCHER, 2001; IVANIČ e CAMPS, 2001; MATSUDA, 2001; PRIOR, 2001; STREET, 2009; WINGATE, 2012; D. MURRAY, 2013); 4) a posição (STREET, 2009); 5) a atribuição 
(HYLAND, 1999; JALILIFAR e CHAMRAN, 2012, MASTURA e AZLAN, 2013); 6) a citação (SWALES, 1990; JAKOBS, 2003; PECORARI, 2006; PETRIĆ, 2007; CLUGSTON, 2008; HARWOOD, 2009; MACEDO e PAGANO, 2011; JALIFAR e CHAMRAN, 2012; MASTURA e AZLAN, 2013); 7) a paráfrase (KECK, 2006): 8) a intertextualidade transgressiva (CHANDRASOMA; THOMPSON E PENNYCOOK, 2004); 9) o plágio (HOWARD, 1993; 1995; PECORARI, 2003); e 10) o "patchwriting" (HOWARD 1995; PECORARI 2006).

Convém, no entanto, acrescentar que alguns dos conceitos mencionados (a atribuição, a citação, a paráfrase) confluem para a originalidade através da capacidade que o autor manifesta de os trabalhar no intento de passar ao leitor a ideia de que conhece o texto que escreveu. Quer isto dizer que o autor teceu o texto conhecendo bem o método a seguir para, por um lado, lhe transferir a voz, a autoria e a originalidade expectadas e para, por outro lado, evitar um percurso que o conduza à intertextualidade transgressiva, ao "patchwriting" e ao plágio. Importa lembrar que a noção de autoria não se revestiu sempre do sentido que detém hoje no nosso contexto; o mesmo se passa com a noção de plágio, que pode inclusive oferecer visões distintas em função das culturas em causa (HOWARD, 1995; ver, também a respeito do efeito da cultura na prática de atribuição e cópia de fontes e da leitura de plágio ao longo dos tempos, PENNYCOOK, 1996; SHI, 2004; KECK, 2006). A ocorrência neste texto de "patchwriting" ao lado de plágio é defensável, dado que o primeiro termo pode cobrir uma forma de escrita admitida por alguns também como plágio (ver HOWARD, 1993; 1995). Howard (1993) vê todavia algo de positivo, em termos de estratégia de composição, no "patchwriting", que define como "copying from a source text and then deleting some words, altering grammatical structures, or plugging in one-for-one synonym substitutes" (p. 233), porque descortina nessa cópia "a healthy effort to gain membership in a new culture" (p. 236). A alusão ao "patchwriting" como oportunidade pedagógica volta a ser realçada pela mesma autora no seu artigo de 1995. Não nos parece desapropriado tirar o maior partido pedagógico do "patchwriting" numa fase incipiente da elaboração de um texto académico, mas nunca num estádio final, como meio de fazer com que o estudante possa aprender com essa atuação a melhor manipular uma linguagem, a académica, que domina logicamente com menos propriedade no princípio da sua carreira (ver, por exemplo, KECK, 2006). A cópia, por exemplo, como sugere Shi (2004, p. 191), pode ser explorada num cenário de aprendizagem. Uma leitura desta ordem é também oferecida em relação ao plágio. Pennycook (1996), alavancado no questionamento de uma estudante acerca da relação entre a postura antiplágio e uma melhor aprendizagem, acaba por transcrever o pensamento dessa estudante de que retomamos a última frase: "[...] Perhaps plagiarism is a way of learning" (p. 225) Da mesma opinião, no atinente ao plágio, é também Starfield (2002). Ensinar a resumir passando por um uso adequado da paráfrase pode ser um procedimento a seguir para evitar a utilização verbatim das fontes (HOWARD, 1995; YANG e SHI, 2003; SHI, 2004; KECK, 2006). Howard (1995) mostra como se deve ensinar a ler e a escrever acerca de textos que podem ser considerados difíceis. A proposta de Howard (1995) aproxima-se em tão alto grau da cópia diferida proposta por Andrée Girolami-Boulinier para reeducar crianças com problemas de ortografia partindo da técnica da leitura direta silenciosa (GIROLAMI-BOULINIER e COHEN-RAK, 1985; PINTO, 1998) que não nos coibimos de reproduzir a seguinte passagem:

Summarizing texts without simultaneously looking at those texts is an invaluable academic skill. Students should learn that the wrong question to ask is "How else can I say this?" Instead, they should learn to read until they understand; then write without looking at the source; and then return to the source to check accuracy and comprehensiveness and to see if any passages are sufficiently similar that they should quote them exactly (HOWARD, 1995, p. 801).

Este excerto coloca-nos de uma forma única não só diante de uma abordagem multicognitiva conforme é proposta por Odisho (2003; 2007; 2014), 
mas também perante uma verdadeira lição para quem está a enfrentar o texto académico no princípio da sua carreira como autor. De facto, é fácil cair na cópia, torna-se uma tentação reproduzir (a propósito da memorização em certas culturas e do que esta pode servir de meio à reprodução, ver a leitura crítica de PENNYCOOK, 1996) quando não se possui o conhecimento suficiente da matéria ou linguístico para parafrasear com perícia as fontes que a ela se reportam ou quando se encontra dificuldade em escrever resumos vistos como um texto que demonstre que quem o escreve consegue separar o acessório do essencial, combinar e generalizar ideias e ir ao cerne do assunto usando frases suas que o traduzam (SHI, 2004).

\section{A complementaridade dos conceitos apresentados num contexto de originalidade}

De um modo ou de outro, estarão implicados neste texto todos os termos supramencionados que vinculámos à originalidade; aliás, alguns já foram aflorados, porque concorrem para observar em mais pormenor a construção da escrita (académica), na qualidade de processo visto de um modo englobante. É que não o conseguimos descontextualizar, alhear do social, e consequentemente afastá-lo da viragem social ("social turn") (TRIMBUR, 1994) que a escrita na era do pós-processo reivindica como seu atributo (ATKINSON, 2003a; 2003b; CASANAVE, 2003; HYLAND, 2003; MATSUDA, 2003). A nossa leitura de escrita como processo distancia-se portanto de um ato meramente individualista/expressivista (MATSUDA, 2003) porque não o vemos coadunar-se com uma atividade desgarrada de outras práticas verbais impregnadas de social (ver PRIOR, 2001). Não afirmamos que nos situamos, no plano da escrita, na era do pós-processo (ATKINSON, 2003), na medida em que não idealizamos a escrita como processo disjunto de uma atividade cultural com fortes ligações a uma literacia sociocultural, que não é passível de descontextualização na sua qualidade de prática social (SOARES, 2001). Nesta linha, quando Casanave (2003) alude à escrita como processo sociopolítico, evidencia o interesse que, a partir de certo momento, a contextualização dos vários aspetos ligados ao processo da escrita passou a ocasionar. O seguinte excerto prova bem essa transição: "In recent years, we have become more interested than in the past in how the cognitive, expressive, and linguistic aspects of writing processes are embedded in social and political contexts of writing, and how all these aspects of writing interact to get writing accomplished" (CASANAVE, 2003, p. 90).

\section{As fontes na escrita académica}

Atendendo a que temos como finalidade tratar principalmente da escrita académica, sobressaem de imediato as fontes como variável que comprova o cariz sociocognitivo desse género textual. Porquanto se augura que quem pratica este género combine, em texto, o seu conhecimento (obtido não só individualmente) sobre um certo tema com outras visões que as fontes lhe aportam, servindo para o confirmar ou para o refutar, é possível ver neste encontro de vozes, que se estima consentâneo com a devida integração textual (SHI, 2004), um jogo assente numa reciprocidade entre o intrapsíquico e o interpsíquico, na terminologia vygotskiana, e a presença de uma escrita situada, que não se restringe por isso a um ato de escrever individual (PRIOR, 2001). Trata-se de uma escrita que ultrapassa, em muito, a soletração ou até o mero grafismo, uma vez que "emerges as a confluence of many streams of activity: reading, talking, observing, acting, making, thinking, and feeling as well as transcribing words on paper" (PRIOR, 2001, p. 57). Aproxima-se esta escrita plural da aceção de literacia no seu sentido sociocultural e não simplesmente psicocognitivo (DE LEMOS 2002), em virtude de englobar variados aspetos que lhe estão associados (MATSUDA, 2003) incluindo uma componente cultural (ATKINSON, 2003a).

Se a escrita académica é um argumento, poderá desde já afiançar-se que a sua originalidade está sempre salvaguardada pela configuração que assumir o que se anseia defender por meio também 
de provas, numa mescla de "verdade contextualizada" e de "verdade interpretada" (SKELTON, 1997), sustentáculos da voz/opinião do autor (ver IRVIN (2010) e, para uma problematização em torno da argumentação, WINGATE, 2012). Ao valer-se das autoridades que consultou sobre o tópico ("verdade contextualizada"), o autor encarregar-se-á de acionar concomitantemente 0 conhecimento que foi acumulando por vias distintas para, ao "dialogar" com essas fontes, organizar os seus pensamentos de modo a tornar original a sua argumentação. Para esse fim, socorre-se da sustentação esperada no âmbito do tema em debate, materializando assim a focada "verdade interpretada", sem a qual não se comprova nem a transformação, nem a inovação, nem a recontextualização, nem a cumplicidade na intertextualidade que caracteriza o texto académico. O protagonista da argumentação, o "diretor de(sta) cena", o autor do trabalho, deve transformar os conteúdos dos textos de que se mune, mercê da filtragem/interpretação que deles faz, e desenhar assim a intertextualidade que representa em suma o texto académico (SHI, 2008). O autor não se pode por este motivo cingir a reproduzir os textos de outros (PENROSE e GEISLER, 1994; N. MURRAY, 2012). Se isso ocorresse, demonstraria que a sua escrita carecia do esforço analítico-sintético condizente com a conjugação de "developing ideas up to verbalizing one's thoughts and organizing them into complex textual representations" (JAKOBS, 2003 p. 896). Neste fragmento de Jakobs, constatam-se de um modo naturalmente parafraseado os dois polos presentes no título deste texto: a geração de ideias e a verbalização textualmente mediada das mesmas como forma de as consubstanciar. Importará acrescentar que, associada à voz que personificará o autor, se encontra também o termo "luta". Uma luta que se efetiva num confronto negociado com as fontes para que dela resultem ideias não reproduzidas e por consequência uma voz que, porque habilmente controlada, consegue alcançar a autoridade própria (PRIOR, 2001; STARFIELD, 2002; YANG e SHI, 2003). A reprodução, como formulado, poderá ser positiva e até considerada um degrau pertinente no percurso preparatório da produção textual (HOWARD, 1995; STARFIELD, 2002; SHI, 2004); porém, com o progredir na direção de uma escrita mais consolidada, as exigências aumentam e a atitude do autor terá de as ecoar adaptando-se ao que a comunidade a que pertence aguarda dele através do seu texto. Nesta ótica, calcula-se que os escritos académicos apresentem uma conformação textual que outorgue credibilidade ao trabalho e ao seu autor (a respeito da credibilidade que deve emanar de um texto científico, ver LIBRA, 2001; PARADIS, 2006), para além de assegurar uma boa relação e o ajustado entendimento com a audiência. Como avança Hyland (2004), pode dizer-se que o garante de uma escrita académica com sucesso radica na habilidade de 0 autor controlar a personalidade nos seus textos, de estabelecer solidariedade com os leitores, de admitir pontos de vista alternativos e de avaliar os conteúdos. Imprimese assim ao autor uma tarefa nada simples de estar focalizado simultaneamente em todos os aspetos tidos como essenciais da atividade intrínseca à escrita académica.

\section{Intervenções tendentes a olhar as fontes de modo crítico}

Mencionaram-se, entre outros termos, a autoria, a voz e a atribuição. Como atuar para que os estudantes sintam que, em condições bem estabelecidas, também podem ter voz, também podem ser autores e gerar ideias, sem terem de recorrer inevitavelmente a fontes e à respetiva atribuição?

Não é, contudo, linear que os estudantes apreciem ou aceitem sem reticências escrever um texto de pequenas dimensões sobre uma matéria que se Ihes proponha sem que antes tenham feito pesquisas bibliográficas ou Ihes tenham sido fornecidos artigos sobre a temática em causa. Quando são confrontados com exercícios de escrita desse teor, conforme já nos foi dado vivenciar, instala-se não raras vezes um certo desconforto, alguma resistência, atitudes que nos revelam um 
público que até pode bloquear por não saber beneficiar da sua experiência de vida, do que lhe foi dado observar na sua existência, do que já leu, do que já escreveu, das conversas que teve com outras pessoas, do tanto que deve ter pensado e sentido e das numerosas e diversificadas atividades realizadas para, por essas vias, compor um texto só seu com uma voz, uma posição, de onde não emirjam interferências atribuídas (PRIOR, 2001). Seria pois de esperar que todas essas atividades capacitassem os estudantes para serem agentes dos seus escritos sem o recurso incondicional à bibliografia fornecida para o efeito. Uma perspetiva que vai nesse sentido é justamente valorizada pela pedagogia baseada no processo (MATSUDA, 2003). Penrose e Geisler (1994) também advogam que se criem situações em que os estudantes olhem os problemas a partir de si próprios em vez de o fazerem a partir do exterior, ou seja, "come to see themselves as participants in, rather than observers of, the construction of knowledge" (p. 517).

Agindo desta forma, os estudantes poderão aperceber-se de que há abordagens à escrita que Ihes dão azo a veicularem a sua voz e a serem autores de pleno direito, mostrando-lhes que estão face a uma realidade e não a uma ficção. Mais, nas circunstâncias, é-lhes dado descobrir que, sabendo tirar partido da sua voz, também conseguem sair vencedores da luta que tantas vezes terão de travar para virem a ser também autores quando se encontrarem confrontados com as ideias dos diversos escritos que vierem a ler. Não devem portanto limitarse a estar arreigados às autoridades estudadas seja por meio de paráfrases mal conseguidas (ver, a respeito dos diversos tipos de paráfrases que vão das quase cópias às revisões substanciais, KECK, 2006), seja através de reproduções literais nem sempre atribuídas com rigor (SHI, 2004). Sucede, porém, que alguns dos escritos produzidos por esta via tomam com frequência a configuração de meras justaposições de frases que mais não são do que um acumular, sem interligação e sem a condigna substância, de respostas às questões que o tema do trabalho não deixa de conter, fazendo-nos pensar no termo "listagem", atribuído por Snowdon (2002) a algumas autobiografias de participantes no "Nun study", que mais não eram do que justaposições de ideias ou acontecimentos. Não será por acaso que Snowdon, na mesma obra, compara autobiografias que denotam um estilo monofónico, as ditas listagens, com outras num estilo, para ele, mais da ordem da alta fidelidade.

Independentemente do que se possa pensar a este respeito, colocar os estudantes numa situação em que tenham de escrever sobre um determinado tópico de improviso e desprovidos de bibliografia torna-se vantajoso porque são obrigados a acionar as suas vozes, fazendo-os reconhecer que não são só as autoridades - os autores das fontes - que têm voz, razão pela qual não as devem seguir cegamente. Basta que se empenhem em conceber a sua própria voz para que possam concluir que ela é uma realidade.

A escrita também pode resultar melhor e apresentar as marcas do género que se pretende trabalhar se os estudantes, na qualidade de leitores, tomarem atitudes acertadas em relação aos textos que consultarem (ver PENROSE e GEISLER, 1994). A dado momento, Penrose e Geisler (1994), firmados na literatura, frisam o interesse de fazer com que os estudantes analisem, sob vários prismas, os textos que tiverem lido a fim de os aliciar, por exemplo, a "to 'mine' the texts they read for strategies they may in turn employ in their own writing" (p. 517). A composição escrita passará então a espelhar a maneira como foi efetuada, nos textos estudados, a leitura dos aspetos formais mais diretamente implicados nos fins ambicionados.

Podemos dizer que foi uma ideia próxima da constante no excerto transcrito, que desconhecíamos à época, que nos levou a elaborar em sessões de um seminário de mestrado por nós orientadas, com base essencialmente na planificação por analogia (HAYES e NASH, 1996), um texto no modo escrito e outro no modo oral sobre um artigo escolhido pelos próprios estudantes, de entre os diferentes textos previamente selecionados e trabalhados criticamente em aula. Serviram de modelo a esta prática de escrita 
colaborativa textos redigidos nesses dois modos propostos por Day (1980) a respeito de um outro tema (ver PINTO, 2012a). O primeiro objetivo deste exercício consistiu em sensibilizar os estudantes para a diferença que representa, em matéria de memória, ler um texto no modo escrito, que permanece o tempo de que o leitor necessitar debaixo do seu controlo visual, ou ouvir um texto no modo oral intencionalmente redigido para ser unicamente ouvido e que, por natureza, escapa ao controlo auditivo depois de ter sido emitido. O segundo objetivo, o mais pertinente neste quadro, fundou-se em consciencializar os estudantes para o trabalho de composição escrita que representa os dois modos indicados. Estamos em crer que um exercício deste género se reveste de grande utilidade na medida em que propicia uma realização, por analogia, de produções textuais que obedecem a uma leitura criteriosa prévia de textos com estruturações similares e obrigam a um bom conhecimento do texto selecionado para praticar a dita planificação por analogia. Para lá disso, excluídas as reformulações comuns a que está sujeito qualquer texto, este exercício obrigou ainda a um trabalho acrescido de reformulação, que contou com a releitura e consequente reescrita dos textos produzidos para que não se notasse que a planificação por analogia partia de modelos escritos em inglês. Vemos de novo, neste caso, a cumplicidade que deve existir entre leitor e escritor. Acresce-se que, na escrita académica, em virtude das suas características, o escritor se encontrará ainda mais associado ao papel de leitor atento e respeitador das convenções prescritas pela comunidade a que pertence ou em que ambiciona integrar-se.

\section{0 modo de usar as fontes e o que requerem de literacia académica}

Enquanto leitor, quem escreve deve aprender a familiarizar-se com a maneira como as fontes são trabalhadas a fim de o resultado final poder ser diferente, original e não reprodutivo, bem como a sentir que os textos não são colagens de citações que acabam por ser inibidoras da emergência do seu poder argumentativo na qualidade de autor (ABASI; AKBARI E GRAVES, 2006). Não podemos esconder que a empresa não é fácil e que o uso das fontes na escrita académica exige habilidades e poder crítico que têm de ser cultivados. Conforme anota Jakobs (2003, p. 901),

\begin{abstract}
[un]certainty in handling the literature, lack of expertise, and deficiencies in knowledge about the forms and functions of references to the literature result in many student papers resembling patchworks of poorly reworked citations rather than consistent scholarly discussions.
\end{abstract}

Se, na linguagem de Abasi; Akbari e Graves, 2006, estamos diante de colagens de citações e, na de Jakobs (2003), estamos perante o termo "patchworks", esta diferença de terminologia não colide com o essencial, ou seja, com a não destreza da parte de quem escreve para percecionar com exatidão o que se espera de um trabalho académico.

A intertextualidade que caracteriza o trabalho científico apoia-se, é certo, numa "verdade contextualizada" como nos lembra Skelton (1997), mas não pode confundir-se com a colagem de citações ou com "patchworks". A verdade contextualizada é incontornável. $\mathrm{O}$ que a constitui deve, todavia, ser utilizado com regra, não cumulativamente, e muito menos verbatim, a fim de que possa emergir do texto que está a ser redigido uma outra voz que objetiva gerir essa informação, controlando a sua integração com vista a fundamentar o que é difundido. Esse apoio na "verdade contextual" não deve por isso ser sinónimo de reprodução das fontes sem qualquer filtragem por parte de quem delas se vale. Dito de outra forma, não se deve passar o tempo nem a citar, nem a remeter por sistema para a literatura lida, sem tirar partido das várias modalidades possíveis de a convocar para o texto em curso quando tal se achar oportuno.

Chegada é a ocasião de olhar mais de perto para as citações atendendo a que se fez menção à "verdade contextual" e ao que ela representa na produção textual científica. Torna-se oportuno referir desde já que o inglês apresenta uma distinção 
terminológica elogiável ao oferecer o termo "citation" paralelamente a "quotation". Jakobs (2003) alerta-nos para o uso inconsistente destes dois termos na literatura que trata da escrita científica e para o facto de, neste seu escrito, empregar "quotation" (p. 897) quando se verifica uma réplica ipsis verbis de uma dada fonte, razão pela qual terão de ser usadas as aspas, e "references to the literature" (p. 897) quando estão em causa referências breves a outros textos que deverão vir logicamente acompanhadas das atribuições. Por sua vez, "citation" é a designação escolhida pelo autor para abarcar ambas as modalidades de recurso às fontes (JAKOBS, 2003, p. 897), correspondendo por conseguinte a um termo mais geral e neutro. Será provavelmente em virtude dessas suas características (geral e neutro) que, na literatura de língua inglesa que consultámos, surgem mais títulos de artigos com o termo "citation" do que com o termo "quotation". Além disso, o termo "citation", entendido como "references to the literature" de acordo com Jakobs (2003), pode tomar a forma integral e não integral (ver, entre outros, SWALES, 1990 e CLUGSTON, 2008) ou ser ou não secundária (PECORARI, 2006; N. MURRAY, 2012). Mesmo não enveredando por uma análise mais fina que conduza às funções das citações (HARWOOD, 2009), as distinções apresentadas já equivalem a instruções relevantes para quem escreve, facto que nos impele a dedicar-lhes, neste texto, algum espaço.

No que concerne à modalidade integral e não integral de citar, no sentido de referir a literatura de acordo com Jakobs (2003), autores como Mastura e Azlan (2013) apresentam uma explicação muito clara de cada um dos dois tipos. Adiantam que "[i]ntegral citations usually contain the name of the cited author within the sentence followed by the year of the author's work" (p. 63) e que "a non-integral citation cites the author's name in parentheses or brackets and is put at the end of a sentence" (p. 63).

Seguem-se dois trechos, extraídos de um trabalho submetido à avaliação numa unidade curricular por nós recentemente lecionada num mestrado, que ilustram respetivamente os dois tipos de citações (integral e não integral) acima definidos (ver sublinhados):

Paradis [ano] considera o "bilinguismo" numa perspectiva que integra a ideia de que os bilingues não constituem um grupo homogéneo.

O termo aquisição de segunda língua referese ao processo de desenvolvimento de competência gramatical e comunicativa numa segunda língua [autores, ano e página].

Os dados que ocorrem no interior dos parênteses retos, destinados a marcarem que o texto foi truncado, foram por nós inseridos e surgem a substituir propositadamente o que constava nas versões originais. Nos restantes exemplos, que figuram nesta secção para sustentar outros aspetos achados pertinentes, foi adotado idêntico procedimento.

A distinção entre citação/referência à literatura integral e não integral (ver também PETRIĆ, 2007) devia ser dada obrigatoriamente a conhecer aos estudantes que teimam em ir justapondo, ao longo dos trabalhos, ideias que não lhes pertencem, limitando-se a adicionar no fim de cada parágrafo o nome do autor consultado e o ano da obra. Sem contestação, revela-se uma necessidade sensibilizar estes estudantes para a possibilidade de distribuírem de modo equilibrado nas suas produções textuais o emprego de citações/referências à literatura não integrais e integrais, recorrendo para as integrais, nas alturas precisas, às expressões que melhor se prestam ao seu encaixe nos textos que têm em mãos (ver PICKARD, 1995; THOMPSON; TRIBBLE, 2001; HYLAND, 2008). O facto de os estudantes optarem ora pela colocação, entre parênteses no final da frase, do nome do autor e do ano da fonte (citação/referência à literatura não integral), ora pela inserção com mais propriedade do nome do autor e do ano da fonte na frase com que pretendem propagar 0 pensamento desse autor (citação/referência à literatura integral) permite-lhes certamente que redijam textos em que espelhem com mais vivacidade a autoria das vozes originais e a preocupação em criar alguma intertextualidade, 
conquanto em determinados momentos ainda possa revestir um cariz transgressivo. Malgrado o cunho porventura transgressivo da intertextualidade por eles produzida nas primeiras tentativas, à semelhança do que propõe Howard (1995) para o "patchwriting", poderíamos também reconhecer nesse tipo de recuperar as fontes tempos de aprendizagem, de "oportunidade pedagógica" citando literalmente Howard (1995, p. 788), que servirão sem dúvida de ponte para a almejada intertextualidade.

Estas duas modalidades de referenciar as fontes são da maior relevância para que os estudantes ganhem uma certa flexibilidade na sua gestão das mesmas sem caírem em formulações que fazem dos seus textos perfeitas sobreposições de referências à literatura consultada. No entanto, cabenos trazer também a terreiro as citações secundárias reiterando o que sobre o assunto escrevem Pecorari (2006) e N. Murray (2012). Cremos nós também que as fontes secundárias devem ser evitadas em favor do uso da fonte primária, sempre que esta seja acessível e esteja escrita numa língua dominada pelo interessado. Usando fontes secundárias, nunca sabemos se não estamos, como afirma Paradis (2006), a perpetuar um mito que tem a sua génese em leituras incorretas das fontes primitivas. Em alguns casos, só podemos ver uma atitude de comodismo quando se verifica o recurso a essas fontes e não às primárias, que correspondem não poucas vezes a obras de fácil acesso que trariam com certeza uma maior sustentação ao trabalho em composição, para além de garantirem sem dúvida conhecimentos complementares de interesse. Afinal, são pormenores deste teor que fazem distinguir os textos de divulgação e jornalísticos dos verdadeiros textos científicos. A diferença de objetivos dos tipos de textos apontados e das audiências a que se destinam representa o suficiente para imprimir à escrita uma estruturação completamente diversa. Disso, não podem os autores de trabalhos académicos alhear-se na busca de alguma facilidade. A escrita, especificamente a académica, a que nos interessa neste enquadramento, é uma luta (ALLEN, 2010), é trabalho e assim deve ser ponderado, dado que, como bem nota D. Murray (2013, p. 24), "Writing is not a mystery. It is a craft, a habit, a discipline that can be understood and practised". Se a escrita académica é tudo isso, tergiversar está fora de questão e temos mesmo de seguir o regulamento que a controla.

Uma tarefa inerente à escrita académica que também pode servir de pretexto para intervir pedagogicamente reporta-se ao uso de citações diretas ("quotations"). À primeira vista, pode figurar-se tarefa simples; contudo, não somos sempre confrontados com o seu emprego correto. Não se trata efetivamente de um expediente que deva ser utilizado com frequência. Ademais, as citações não devem ser demasiado longas porque, no fundo, elas devem servir unicamente para documentar cirurgicamente qualquer ideia que se está a apresentar. Por outro lado, não devem oferecer o aspeto de frases desagregadas do resto to texto ou ocupar um parágrafo completo.

Os quatro excertos seguintes, retirados de textos de estudantes que frequentaram unidades curriculares que tivemos a nosso cargo a nível de mestrado, em edições diferentes, ilustram o que se encontra expresso na frase final do parágrafo precedente:

[...] "MMA is an attempt at duplicating the natural manner in which child acquires language" [autor, ano e página]. [...]

[...] "All of these have different accents and partly different vocabularies and grammars". [autor e ano]. [...]

Citando mais uma vez Odisho: "Usually adults display considerable cognitive conditioning and bias to the native language phonetic and phonological rules and constraints and thus develop a kind of resistance to L2/FL acquisition/arning which was described earlier on as psycholinguistic deafness to replace the traditional fossilization." [autor, ano e página]

Grosjean [ano e página] defende "the 'real' bilingual has long been seen as the one who is equally and fully fluent in two languages", acrescenta ainda, "the ideal bilingual subject is the one who does as well in one language as in the other. All other subjects are somehow 'less bilingual' and are put into an indeterminate category - they are neither monolingual nor 'really bilingual'", 
continuando, "the bilingual is not the sum of two complete or incomplete monolinguals but a unique and specific speaker-hearer. [...] Bilingualism is the regular use of two (or more) languages, and bilinguals are those people who need and use two (or more) languages in their everyday lives".

Resta então chamar a atenção para a maneira como se integram as citações ("quotations") no texto que se está a redigir, porque esse exercício reclama algum grau de literacia académica (PETRIĆ, 2012). A este respeito, Jakobs (2003) faz a distinção entre a integração cotextual e contextual das citações diretas. No caso da integração cotextual, é necessário preparar a citação em função do texto de acolhimento, adaptando-o do ponto de vista morfológico, sintático ou ortográfico (PETRIĆ, 2012). Como refere Petrić, trata-se de uma incorporação da citação no texto que se está a redigir. Este procedimento, todavia, pode oferecer dificuldade a quem se está a iniciar neste tipo de escrita e a quem não domine suficientemente a língua da fonte usada, uma vez que demanda em diversas ocasiões a eliminação ou inserção de palavras ou de passagens, razão pela qual se torna não raras vezes um bom motivo para atuar pedagogicamente.

Nos três fragmentos, abaixo transcritos, de textos de estudantes de mestrado que frequentaram unidades curriculares que ministrámos, regista-se a mencionada falta de integração cotextual (ver sublinhados):

Recorrendo ainda a Pinto, relativamente ao estudo de Day acerca dos "language-bound" e "language optional", que nos indica que "the "language-bound" (LBs), the ones who "report what the language allows, not the stimulus events" and the "language optional" (LOs), the ones who "are able to use rules or set them aside, depending on task demands." [autor e ano, in autor e ano], caraterizo a minha utilização da língua segunda opcional, logo, LO.

Grosjean [...] propondo uma visão holística do bilinguismo, que considera como sendo "the regular use of two (or more) languages", tornando um bilingue "those people who need and use two (or more languages) in their everyday lives [ano e página].

O sujeito é introvertido, de nacionalidade portuguesa e sempre residiu nesse país, dominando somente a sua língua nativa, conceito que Paradis descreve como "the native language, that is the first language acquired in infancy" [ano e página].

A integração contextual prende-se com a adequação das palavras de outros ao que se está a transmitir, ou seja, com a oportunidade de que se reveste recorrer ao testemunho de terceiros, por meio de citações ipsis verbis, quando se está a expor uma dada matéria (ver PETRIĆ, 2012). Não é pouco comum verificar-se que os estudantes citam passagens que não evidenciam qualquer relação com o que estão a argumentar.

Seguidamente, apresentamos três passagens extraídas de textos de estudantes de uma unidade curricular de um mestrado de que fomos docente que revelam que os seus autores não articulam devidamente o que expõem com as citações de que se socorrem para justificar o seu pensamento (ver sublinhados):

Penso que posso afirmar, através das palavras de Paradis, que sou uma pessoa bilingue, pois "a dominant bilingual is a person who speaks one language better (more fluently or accurately) than the others [...]" [autor e ano].

Entre estas teorias extremistas existem algumas, como a utilizada por Harris que se colocam entre estas duas: "Bilingualism is the regular use of two (or more) languages, and bilinguals are those people who need and use two (or more) languages in their everyday lives" [autor, ano e página].

Como propõe Pinto [ano e página] que deve ser feita uma anamnésia dos alunos a ensinar para conhecer a sua história linguística e saber quais as motivações que os levam a aprender a língua segunda. Reforçado por McLaughlin [ano] second language learning by school-aged children takes longer, is harder, and involves a great deal more than most teachers have been led to believe. We need consciously to rethink what our expectations should be.

Acresce-se ao relatado a obrigatoriedade de acompanhar a citação direta ("quotation"), sempre colocada entre aspas, da página da obra de onde foi extraída, para além do(s) nome(s) do(s) autor(es) e da data da obra em causa. São talvez dados tidos por muitos como triviais e que nem deveriam ser evocadas neste âmbito. Certo é que não aparecem 
por sistema nos trabalhos redigidos pelos estudantes como comprovam alguns dos exemplos fornecidos, expressamente truncados nos momentos onde ocorriam as fontes explícitas. Com o fim de fornecer a informação esperada, adicionou-se nos espaços delimitados pelos parênteses retos a indicação genérica de nome(s), ano e página quando assinalados. Sucede que a falta de rigor na referência às fontes só pode dar azo a leituras que levem a questionar a credibilidade dos trabalhos.

\section{Da génese das ideias à sua concretização na escrita académica: uma marca identitária}

Intimamente relacionado com a capacidade de citar, no seu sentido mais abrangente, com correção encontra-se o conceito de intertextualidade (SHI, 2008), que remete para o que se deve entender por texto académico na qualidade de espaço de interseção das ideias de quem o escreve com as de terceiros (SHI, 2004).

Cumpre a quem comenta a escrita académica dos estudantes em início de carreira mostrar-lhes como sair do "patchwriting", do "patchwork", das "colagens" para transitarem, com o à-vontade possível, para a intertextualidade. Noutras palavras, é imperioso que esses estudantes conheçam as regras da escrita preceituada pela comunidade científica da sua área e que venham paulatinamente a dominar a literacia académica que terão de deter para integrar mais cedo ou mais tarde, se assim determinarem, essa comunidade.

Noutros textos (PINTO, 2014) foram especialmente tratados aspetos ligados à escritacomposição que objetivavam respeitar todos os pormenores que contribuíssem para que ela resultasse clara, lógica e inequívoca ao leitor. Convocaram-se para 0 efeito recomendações extraídas de Lanham (2006) e de D. Murray (2013). De Lanham (2006), recomendou-se que se respeitasse o seu "Método Paramédico" (ver, por exemplo, PINTO, 2012b), um verdadeiro auxiliar para quem tenciona tratar frases consideradas "doentes".
Nesta ocasião, relembrava que uma produção textual clara deve permitir que o leitor encontre facilmente a ação (principal) de cada uma das frases que a integram (regra 3 do Método Paramédico de LANHAM, 2006, p. x), cuja redação deve ter respeitado a regra 5 do referido método (LANHAM, 2006, p. x), isto é: "Start fast - no slow windups". Para que tal aconteça com as desejadas implicações positivas na audiência, desaconselha-se, sobretudo quando estão em causa frases demasiado longas (ver, no atinente à alternância do tamanho das frases, LANHAM, 2006, p. 42), que os verbos correspondentes às ações principais nelas contidas estejam muito distantes dos respetivos sujeitos. Deve assim quem escreve abster-se de inserir, entre o sujeito e o verbo principal de cada frase, um número exagerado de orações, em grande parte possivelmente relativas, ou de outras formas de adjetivação. Os encaixes à esquerda são de evitar porque contrariam o funcionamento natural da memória que é chamada a intervir para reter a informação veiculada. A escrita deve obedecer preferencialmente a encaixes bem distribuídos. Poderão alguns deles estar situados à esquerda da ação principal da frase, mas também se espera que outros se localizem à sua direita, para que a disposição da informação a comunicar condiga melhor com o processamento inerente à memória compatível com a sua retenção.

De D. Murray (2013), retiraram-se ensinamentos relevantes em termos de uma escrita que deve assentar numa revisão continuada (ver, por exemplo, PINTO, 2013). De N. Murray (2012), por sua vez, sublinhamos, entre os aspetos formais, a importância de se manter uma relação estritamente isomórfica entre as fontes usadas nos textos e as referências finais que deles fazem parte integrante (ver, por exemplo, LIBRA, 2001).

\section{Nota de fecho}

A escrita, como a apreendemos, não é empresa simples e de uma exequibilidade sem contratempos; contudo, se nos ativermos ao recado 
que encerra a frase de Murray (2013, p. 28) "the writing comes in the writing", só podemos concordar com Andrew e Romova (2012) quando assinalam os benefícios de uma escrita com múltiplas versões e aditar que é de toda a conveniência começar com a ideia de que se torna obrigatório rever e reescrever tantas vezes quantas as indispensáveis apoiados em comentários tecidos por leitores bem escolhidos (D. MURRAY, 2013) ou por orientadores competentes.

Justamente a encerrar este texto, cumpre-nos ressaltar que a escrita tem o dom de colocar frente a frente o que se almeja difundir e a forma como se estima fazê-lo num diálogo não forçosamente pacífico e, na maior parte das vezes, moroso.

A escrita académica, por sua vez, apresenta uma maneira muito própria de pôr o seu autor na busca de ideias próprias, geradas seja por via contextual seja por meio de provas empíricas, que não são poupadas à interpretação que assegurará o seu grau de originalidade. A escrita em destaque não se limita porém à geração de ideias. Aguarda-a a literacia académica que é chamada a intervir quando é chegada a hora de plasmar as ideias geradas. Ao longo deste texto, partilharam-se alguns assuntos que não devem ser, em nossa opinião, debatidos com leveza e focalizaram-se noções que esperemos tenham suscitado no leitor a vontade de olhar com mais profundidade para uma temática que merece ser equacionada e problematizada sob vários ângulos.

\section{Referências}

ABASI, Ali R.; AKBARI, Nahal; GRAVES, Barbara. Discourse appropriation of identities, and the complex issue of plagiarism: ESL students writing in graduate school. Journal of Second Language Writing, v. 15, p.102-117, 2006.

ALLEN, Sarah. The inspired writer vs. the real writer. In: LOWE, C.; ZEMLIANSKY, P. (Eds.). Writing spaces: Readings on writing. Vol. 1. Anderson SC: Parlor Press, 2010, p. 34-44. Disponível em: $<$ http://writingspaces.org/essays > Acesso em: 12-052015.

ANDREW, Martin; ROMOVA, Zina. Genre, discourse and imagined communities: The learning gains of academic writing learners. Journal of Academic Language \& Learning, v. 6, n. 1, p. A77-A88, 2012.
ATKINSON, Dwight. Reflections and refractions on the JSLW special issue on voice. Journal of Second Language Writing, v. 10, p. 107-124, 2001.

L2 writing in the post-process era: Introduction. Journal of Second Language Writing, v. 12, p. 3-15, 2003a.

Writing and culture in the post-process era. Journal of Second Language Writing, v. 12, p. 49-63, 2003b.

BEREITER, Carl; BURTIS, P. J.; SCARDAMALIA, Marlene. Cognitive operations in constructing main points in written composition. Journal of Memory and Language, v. 27, p. 261-278, 1988.

BUNN, Mike. How to read like a writer. In: LOWE, C.; ZEMLIANSKY, P. (Eds.). Writing spaces: Readings on writing. Vol. 2. Anderson SC: Parlor Press, 2011, p. 71-86. Disponível em: <http://writingspaces.org/essays>. Acesso em: 12-052015.

CASANAVE, Christine Pearson. Looking ahead to more sociopolitically-oriented case study research in L2 writing scholarship (But should it be called "postprocess"?). Journal of Second Language Writing, v. 12, p. 85-102, 2003.

CHANDRASOMA, Ranamukalage; THOMPSON, Celia; PENNYCOOK, Alastair. Beyond plagiarism: Transgressive and nontransgressive intertextuality. Journal of Language, Identity, and Education, v. 3, n. 3, p. 171-193, 2004.

CHENOWETH, N. Ann; HAYES, John R. The inner voice in writing. Written Communication, v. 20, n. 1, p. 99-118, 2003.

CLUGSTON, Marie. An analysis of citation forms in health science journals. Journal of Academic Language \& Learning, v. 2, n. 1, p. A11-A22, 2008.

CROWLEY, Sharon. Components of the composing process. College Composition and Communication, v. 28, n. 2, p. 166-169, 1977.

CURRIE, Pat. Staying out of trouble: Apparent plagiarism and academic survival. Journal of Second Language Writing, v. 7, n. 1, p. 1-18, 1998.

DAY, Ruth S. Teaching from notes: Some cognitive consequences. In: MCKEACHIE, W. J. (Ed.). New directions for teaching and learning: Learning, cognition, and college teaching. San Francsico: Jossey-Bass, 1980, p. 95-112.

DE LEMOS, Marion. Closing the gap between research and practice: Foundations for the acquisition of literacy. Melbourne, Australian Council for Educational Research (ACER) (47 pp.), 2002. Disponível em:

$<$ http://research.acer.edu.au/cgi/viewcontent.cgi?articl $\mathrm{e}=1001 \&$ context=literacy_numeracy_reviews $>$.

Acesso em: 16-05-2015. 
EMIG, Janet. Writing as a mode of learning. College Composition and Communication, v. 28, n. 2, p. 122128, 1977.

FAIGLEY, Lester. Competing theories of process: A critique and a proposal. College English, v. 48, n. 6, p. 527-542, 1986.

FAIGLEY, Lester; WITTE, Stephen. Analyzing revision. College Composition and Communication, v. 32, n. 4, p. 400-414, 1981.

GIROLAMI-BOULINIER, Andrée; COHEN-RAK, Nicole. S.O.S. au C.E.S. Bulletin de la Société Alfred Binet et Théodore Simon, v. 604, n. III, p. 6-14, 1985.

HARWOOD, Nigel. An interview-based study of the functions of citations in academic writing across two disciplines. Journal of Pragmatics, v. 41, p. 497-518, 2009.

HAYES, John R.; FLOWER, Linda S. Writing research and the writer. American Psychologist, v. 41, n. 10, p. 1106-1113, 1986.

HAYES, John R.; NASH, Jane G. On the nature of planning in writing. In: LEVY, C. M.; RANSDELL, S. (Eds.). The science of writing. Theories, methods, individual differences, and applications. Mahwah, New Jersey: Lawrence Erlbaum Associates, Publishers, 1996, p. 29-55.

HIRVELA, Alan; BELCHER, Diane. Coming back to voice. The multiple voices and identities of mature multilingual writers. Journal of Second Language Writing, v. 10, p. 83-106, 2001.

HOWARD, Rebecca Moore. A plagiarism pentimento. Journal of Teaching Writing, v. 11, n. 3, p. 233- 245, 1993.

Plagiarisms, authorships, and the academic death penalty. College English, v. 57, n. 7, p. 788-806, 1995.

HYLAND, Ken. Academic attribution: Citation and the construction of disciplinary knowledge. Applied Linguistics, v. 20, n.3, p. 341-367, 1999.

Genre-based pedagogies: A social response to process. Journal of Second Language Writing, v. 12, p. 17-29, 2003.

Disciplinary interactions: Metadiscourse in L2 postgraduate writing. Journal of Second Language Writing, v. 13, p. 133-151, 2004.

As can be seen: Lexical bundles and disciplinary variation. English for Specific Purposes, v. 27, p. 4-21, 2008.

IRVIN, L. Lennie. What is "academic" writing? In: LOWE, C.; ZEMLIANSKY, P. (Eds.). Writing spaces: Readings on writing. Vol.1. Anderson SC: Parlor Press, 2010, p. 3-17. Disponível em: http://writingspaces.org/essays. Acesso em: 12-052015.

IVANIČ, Roz; CAMPS, David. I am how I sound. Voice as self-representation in L2 writing. Journal of Second Language Writing, v. 10, p. 3-33, 2001.

JAKOBS, Eva-Maria. Reproductive writing - writing from sources. Journal of Pragmatics, v. 35, p. 893906, 2003.

JALILIFAR, Alireza; CHAMRAN, Shahid. Academic attribution: Citation analysis in master's theses and research articles in applied linguistics. International Journal of Applied Linguistics, v. 22, n. 1, p. 23-41, 2012.

JUEL, Connie. Learning to read and write: A longitudinal study of 54 children from first through fourth grades. Journal of Educational Psychology, v. 80, n. 4, p. 437-447, 1988.

JUEL, Connie; GRIFFITH, Priscilla L.; GOUGH, Philip B.. Aquisition of literacy: A longitudinal study of children in first and second grade. Journal of Educational Psychology, v. 78, n. 4, p. 243-255, 1986.

KECK, Casey. The use of paraphrase in summary writing: A comparison of $\mathrm{L} 1$ and $\mathrm{L} 2$ writers. Journal of Second Language Writing, v. 15, p. 261-278, 2006.

LANHAM, Richard A. Revising Prose. Fifth Edition. New York: Pearson Longman, 2006.

LIBRA, Judy A. How to Write a Paper. Introduction to Scientific Work Seminar, Module 6. International Study Course Environmental and Resource Management, Brandenburg Technical University Cottbus, Germany, 2001. Versão enviada pela autora.

MACEDO, Tatiana S. de; PAGANO, Adriana Silvano. Análise de citações em textos acadêmicos escritos. Revista D.E.L.T.A, v. 27, n. 2, p. 257-288, 2011.

MARCUSCHI, Luiz Antônio. Da fala para a escrita. Atividades de retextualização. 2. ${ }^{\text {a }}$ edição. São Paulo: Cortez Editora, 2001.

MASTURA, Nik; AZLAN, Nik Ismail. Citation typologies and rhetorical functions of citations in master dissertations. Creative Practices in Language Learning and Teaching, v. 1, n. 2, p. 61-74, 2013. Disponível $<$ http:/www kedah uitm edu my/CPLT/images/stories/ v1n2/Article5.pdf $>$. Acesso em: 6-08-2015.

MATSUDA, Paul Kei. Voice in Japanese written discourse. Implications for second language writing. Journal of Second Language Writing, v. 10, p. 35-53, 2001.

Process and post-process: A discursive history. Journal of Second Language Writing, v. 12, p. 65-83, 2003. 
MURRAY, Donald M. Write before writing. College Composition and Communication, v. 29, n. 4, p. 375381, 1978.

The craft of revision. Fifth Anniversary Edition. Boston: Wadsworth Cengage Learning, 2013.

MURRAY, Neil. Writing essays in English language and linguistics. Principles, tips and strategies for undergraduates. Cambridge: Cambridge University Press, 2012.

ODISHO, Edward. Y. Techniques of teaching pronunciation in ESL, bilingual \& foreign language classes. Lincom Language Textbooks 05. München: Lincom Europa, 2003.

ODISHO, Edward Y. A multisensory, multicognitive approach to teaching pronunciation. Linguística. Revista de Estudos Linguísticos da Universidade do Porto, v. 2, p. 3-28, 2007.

Pronunciation is in the brain, not in the mouth. A cognitive approach to teaching it. Piscataway, $\mathrm{NJ}$ : Gorgias Press LLC, 2014.

PARADIS, Michel. More belles infidèles - or why do so many bilingual studies speak with forked tongue? Journal of Neurolinguistics, v. 19, p. 195-208, 2006.

PECORARI, Diane. Good and original: Plagiarism and patchwriting in academic second-language writing. Journal of Second Language Writing, v. 12, p. 317345, 2003.

Visible and occluded citation features in postgraduate second-language writing. English for Specific Purposes, v. 25, p. 4-29, 2006.

PENNYCOOK, Alastair. Borrowing others' words: Text, ownership, memory, and plagiarism. Tesol Quarterly, v. 30, n. 2, p. 201-230, 1996.

PENROSE, Ann, M.; GEISLER, Cheryl. College Composition and Communication, v. 45, n. 4, p. 505520, 1994.

PERL, Sondra. Understanding composing. College Composition and Communication, v. 31, n. 4, p. 363369, 1980.

PETRIĆ, Bojana. Rhetorical functions of citations in high- and low-rated master's theses. Journal of English for Academic Purposes, v. 6, p. 238-253, 2007.

Legitimate textual borrowing: Direct quotation in L2 student writing. Journal of Second Language Writing, v. 21, p. 102-117, 2012.

PICKARD, Valerie. Citing previous writers: What can we say instead of 'say'? Hong Kong Papers in Linguistics and Language Teaching, v. 18, p. 89-102, 1995.
PINTO, Maria da Graça L. Castro. Saber Viver a Linguagem. Um Desafio aos Problemas de Literacia. Porto: Porto Editora (Colecção Linguística Porto Editora, 11), 1998.

O interesse prático da linguística aplicada e a sua abrangência em termos de pesquisa. In: DUARTE, I. M.; FIGUEIREDO, O.; VELOSO, J. (Orgs.). A linguagem ao vivo. Textos selecionados de Maria da Graça L. Castro Pinto. Cadernos de Apoio Pedagógico da FLUP C06. Porto: Faculdade de Letras da Universidade do Porto, 2009, p. 153-188.

A leitura e a escrita na universidade. Até onde pode ir o papel da universidade na sua otimização? In: TEIXEIRA e SILVA, R.; YAN. Q.; ESPADINHA, M. A.; LEAL, A. V. (Eds.). A formação de novas gerações de falantes de português no mundo (III SIMELP). China, Macau: Universidade de Macau, CDROM, 2012a, p. 900-907.

Recensão de Richard A. Lanham. Revising Prose. Fifth Edition. New York: Pearson Longman, 2006. Linguarum Arena. Revista do Programa Doutoral em Didática de Línguas da Universidade do Porto, v. 3, p. 147-151, 2012b.

Castro. Recensão de Donald M. Murray. The craft of revision. Fifth Anniversary Edition. Boston: Wadsworth. Cengage Learning, 2013. Linguarum Arena. Revista do Programa Doutoral em Didática de Línguas da Universidade do Porto, v. 4, p. 125-132, 2013.

A escrita. O papel da universidade na sua otimização. C07capflup. Porto: Faculdade de Letras da Universidade do Porto, 2014.

A leitura e a literacia de leitura vistas como etapas do ato de ler. In: NASCHOLD, A. C.; JUNIOR, A. P.; GUARESI, R.; PEREIRA, V. W. (Orgs.) Aprendizado da leitura e da escrita: a ciência em interface. Natal: EDUFRN, 2015, p. 119-142.

PRIOR, Paul. Voices in text, mind, and society. Sociohistoric accounts of discourse acquisition and use. Journal of Second Language Writing, v. 10, p. $55-81,2001$.

ROHMAN, D. Gordon. Pre-writing. The stage of discovery in the writing process. College Composition and Communication, v. 16, n. 2, p. 106-112, 1965.

ROSENBERG, Karen. Reading games: Strategies for reading scholarly sources. In: LOWE, C.; ZEMLIANSKY, P. (Eds.). Writing spaces: readings on writing. Vol. 2. Anderson SC: Parlor Press, 2011, p. 210-220.

Disponível em: <http://writingspaces.org/essays $>$. Acesso em: 12-05-2015.

SHI, Ling. Textual borrowing in second-language writing. Written Communication, v. 21, n. 2, p. 171200, 2004. 
Textual appropriation and citing behaviors of university undergraduates. Applied Linguistics, v. 31, n. 1, p. 1-24, 2008.

SINGER, Jerome L; BARRIOS, Michael V. Writer's block and blocked writers: Using natural imagery to enhance creativity. In: KAUFMAN, S. B.; KAUFMAN, J. C. (Eds.). The psychology of creative writing. Cambridge: Cambridge University Press, 2009, p. 225-246.

SKELTON, John. The representation of truth in academic medical writing. Applied Linguistics, v. 18, n. 2, p. 121-140, 1997.

SNOWDON, David. Aging with grace. The nun study and the science of old age: How we can all live longer, healthier and more vital lives. London: Fourth Estate, 2002.

SOARES, M. Letramento. Um tema em três gêneros. 2. ${ }^{\text {a }}$ edição, 4. ${ }^{\text {a }}$ reimpressão. Belo Horizonte: Autêntica Editora, 2001.

SOMMERS, Nancy.. Response to Sharon Crowley, "Components of the composing process". College Composition and Communication, v. 29, n. 2, p. 209211, 1978.

The need for theory in composition research. College Composition and Communication, v. 30, n. 1, p. 46-49, 1979.

Across the drafts. College Composition and Communication, v. 58, n. 2, p. 248-257, 2006.

STARFIELD, Sue. "I'm a second-language English speaker": Negotiating writer identity and authority in sociology one. Journal of Language, Identity, and Education, v. 1, n. 2, p. 121-140, 2002.

STREET, Brian. "Hidden" features of academic paper writing. Working papers in Educational Linguistics, v. 24, n. 1, p. 1-17, 2009.

SWALES, John M. Genre analysis: English in academic and research settings. $13^{\text {th }}$ printing 2008. Cambridge: Cambridge University Press, 1990.

THOMPSON, Paul; TRIBBLE, Chris. Looking at citations: Using corpora in English for academic purposes. Language Learning \& Technology, v. 5, n. 3, p. 91-105, 2001.

TRIMBUR, John. Review: Taking the social turn: Teaching writing post-process. College Composition and Communication, v. 45, n. 1, p. 108-118, 1994.

VIGOTSKI, L. S. A formação social da mente. O desenvolvimento dos processos psicológicos superiores. In: COLE, M.; JOHN-STEINER, V.; SCRIBNER, S.; SOUBERMAN, E. (Orgs.). Tradução J. Cippola Netto, L. Silveira Menna Barreto, S. Castro Afeche. São Paulo: Martins Fontes, 1996.
YANG, Luxin; SHI, Ling. Exploring six MBA students' summary writing by introspection. Journal of English for Academic Purposes, v. 2, p. 165-192, 2003.

WINGATE, Ursula. 'Argument!' helping students understand what essay writing is about. Journal of English for Academic Purposes, v. 11, p. 145-154, 2012.

ZAMEL, Vivian. Writing: The process of discovering meaning. Tesol Quarterly, v. 16, n. 2, p. 195-209, 1982. 